\title{
The Evolution of Bonded Design: From Elementary School to Higher Education
}

\author{
Valerie Nesset ${ }^{1 *}$, J. Brice Bible ${ }^{1}$, and Nicholas Vanderschantz ${ }^{2}$ \\ ${ }^{1}$ University at Buffalo (SUNY), Buffalo, New York, U.S.A. \\ ${ }^{2}$ University of Waikato, New Zealand \\ \{vmnesset, bible\}@buffalo.edu, vtwoz@waikato.ac.nz
}

\begin{abstract}
This paper introduces an alternative model of the participatory design (PD) methodology, Bonded Design (BD). Bonded Design originated from research investigating the use of participatory design methods to foster collaboration between two potentially disparate groups, adult researchers/designers and elementary school children. Previous work has shown that by using design techniques selected from various existing PD models, executed in a particular order, the Bonded Design methodology can successfully empower two distinct groups of participants to conceive ideas for innovative technologies they could not have produced alone. For these reasons the BD methodology was chosen as the framework for a university-wide initiative of a Research 1 university to foster meaningful communication and interaction between faculty and IT professional staff with the intent to create innovative technology solutions. Findings from this study indicated that while several Bonded Design features were useful in achieving the end goal, modifications needed to be made to the methodology as a whole to accommodate not only the increased sophistication and knowledge base of the adult participants, but also the design of a tangible final deliverable that could be directly implemented.
\end{abstract}

Keywords: Participatory cultures, Participatory Design, Bonded Design, BD, technology solutions

\section{$1 \quad$ Introduction}

In spring 2017, under the purview of the Office of the Vice President-Chief Information Officer of a large Research 1 university in New York State, a university-wide survey of faculty members' IT needs and uses was conducted [1]. It was anticipated that the survey would identify where there were needs for upgrades to hardware and software as well as gaps in IT support services. While these goals were achieved, an unexpected, but important finding was revealed in the open-ended comments where faculty were asked for suggestions to improve IT services. These comments identified a disconnect between faculty and IT professional staff. It appeared that while IT professionals had a good understanding of how particular technologies were designed to work, they were not necessarily aware of how faculty were actually using them. Indeed, although they 
worked for the same institution, neither group seemed to know much about the other. This was not an unusual finding as IT professionals' interactions with faculty are most often limited to troubleshooting problems. Yet, it was clear that to make IT services more responsive to faculty needs, more meaningful communication and interaction needed to be fostered between these two disparate groups. The big question, then, was how? A complex problem, it would not be solved through the administration of another survey. More in-depth research methods were required. Enter the Faculty IT Liaison (FITL) Program.

The FITL Program was developed primarily as a means to facilitate the generation of recommendations for modifications to existing technologies and IT programs and services to make them more faculty-friendly. It was reasoned that this could be best accomplished by bridging the communication and interaction gap between faculty and IT professionals to encourage meaningful collaboration. Participatory design methods have been shown to enable such collaboration [2-4], particularly the participatory design methodology of Bonded Design. Bonded Design [5-7] emerged from research investigating the collaboration between two distinct and disparate groups, adult researchers and children. While the Bonded Design methodology had been used only with intergenerational teams, it was considered a good fit for the FITL Program because it is predicated on the notion that each group possesses unique expertise, and that within the shared experience of the design team, these two groups are able to come together to create something that could not have been created alone or with their peers. Yet, as this would be the first time the methodology would be used with two distinct groups of adults, it was anticipated that some modifications would need to be made.

This paper presents and discusses the modifications to the Bonded Design framework to enable it to be an effective tool to promote better communication and interaction between university faculty and IT personnel to enable development of an innovative and implementable final deliverable.

\section{Bonded Design in the Context of Participatory Design}

The decision to use a participatory design process bringing together faculty members and IT professionals, draws from the literature on user-centered and participatory design [8] and from the researchers' previous experience in developing new approaches to designing technology alongside elementary school students [5-7]. Unlike some usercentered design (UCD) approaches that may only include end-users in certain stages of development such as system testing, [9] participatory design promotes a design process that is not just human-centered, but rather, human-involved. Marti and Bannon [10] describe this as, "users are not simply viewed as objects of study but as active agents within the design process itself...so those who will be affected by change have an influence on the kind of changes that will be made" (p. 8). In participatory design, users move from extrinsic roles (e.g., observer) to intrinsic roles (e.g., peer co-designer) [911]. Participatory design has flourished in recent decades and has evolved into many different approaches with different methods of engaging end-user communities in the design process. For example, participatory design techniques have been used to design 
more user-friendly systems with and for children [8, 12-14], in planning library spaces [15], and in business [16]. What unites these approaches is the over-arching concept of active participant involvement leading to better outcomes. What differentiates these approaches is the level and duration of the participants' involvement [9]. As Bowler et al. [17] assert, "participatory design recognizes that users are the experts in how they will use technology in the real world and that they should, therefore, be part of the design process. The single-most important characteristic of participatory design and one that distinguishes it from other methods which incorporate a face-to-face interaction with users, is that users are "in essence co-designers" throughout an iterative, circular process of design" (p. 734). Thus, PD takes on aspects of action research, promoting through a reflective process the collaborative solving of real-world problems directly affecting its participants [18-20].

Bonded Design (BD) emerged from research investigating how children design web portals [21]. BD integrates elements of participatory design and user-centered design approaches, especially those of Cooperative Inquiry [12] and Learner-Centered Design [22-23], bringing two disparate groups together in the shared experience of the design team. Its team approach, where participants are considered equal but different, each sharing their own expertise with their teammates throughout the design process was considered ideal for bringing together faculty members and IT professionals. Another reason it seemed the best fit as a framework for the FITL Program was its flexible methodology consisting of seven different design techniques: needs assessment, or determining what the user community wants in terms of design deliverable; evaluation through team discussion of exemplars of similar technology designs; discussion of design issues; brainstorming design ideas (where all ideas, no matter how whimsical, are given equal value); prototyping low-tech models of potential designs; and consensus building related to the final design of the low-tech prototype.

\section{The Evolution of Bonded Design}

This section will describe and explain the Bonded Design model/methodology in the context of the original intergenerational team studies and its recent use in the Faculty IT Liaison Program, outlining the changes made to accommodate the latter, and why they were made.

\subsection{Purpose of the Studies}

The purpose of the original study was to determine if intergenerational teams could work together to develop a low-tech prototype of a technology, specifically, a web portal as the researchers had expertise in web portal design. The Bonded Design methodology/model [5-7] emerged from the data collected during the design sessions. In the university study, however, it was the Bonded Design methodology itself that was under investigation - how efficacious it was in fostering meaningful communication and collaboration to produce a tangible final deliverable in an organization-wide environment 
where instead of intergenerational disparity, there was now employee hierarchy disparity. Differing from the original BD use case that explored web portal design, the final deliverable in this case were recommendations to make three everyday technologies email, course management software, and data storage - more faculty-friendly to use.

\subsection{The Origins of the Bonded Design Methodology}

As it was the results of the original studies [5-7] that informed the Bonded Design methodology, it is necessary to briefly revisit how they were formed. To structure the intergenerational team design sessions, several design techniques were selected from different participatory design models including Co-operative Inquiry [12], Informant Design [24], Contextual Design [25] and Learner-Centered Design [22-23]. Bonded Design is comprised of those techniques that were found to be the most effective in encouraging the two groups to communicate and collaborate.

As shown in Figure 1, the original Bonded Design methodology/framework consists of two groups, designers and users, that collaborate in the shared experience of the design team. The design sessions are structured using the six design techniques which are accomplished individually or in teams, depending on the activities associated with a particular technique. The design techniques are applied in a specific order, leading to the creation of a team low-tech prototype.

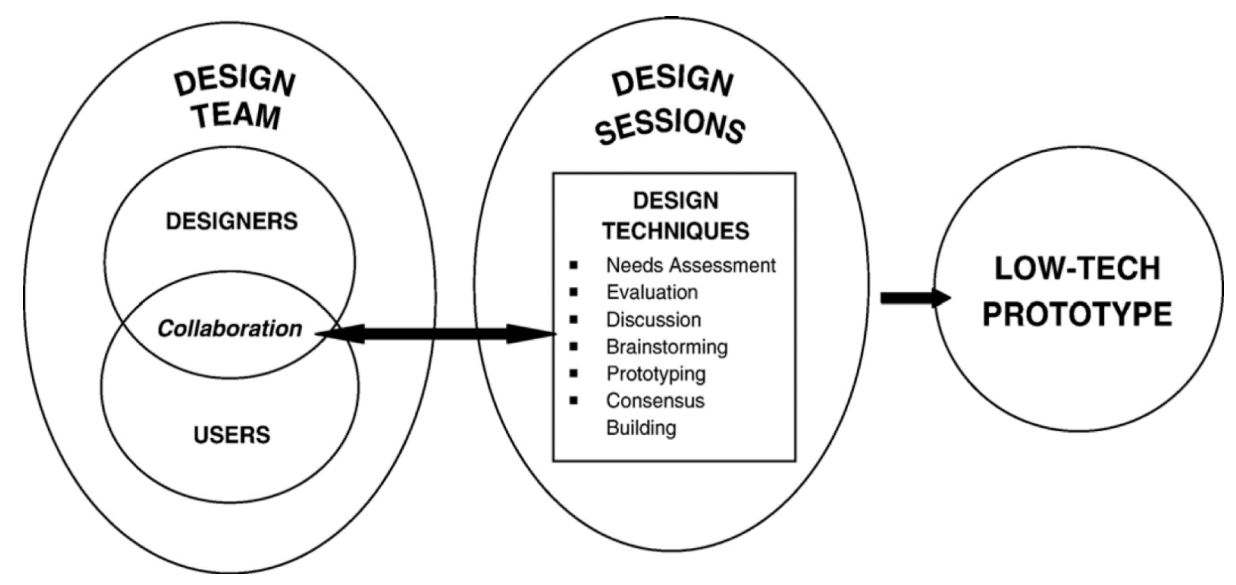

Fig. 1. Original Bonded Design Model [5-7]

\subsection{Design Team Recruitment, Makeup and Authority Issues}

In terms of recruitment, in the original studies, volunteer student names were picked randomly from a hat. As this was not a feasible nor desirable method for the much larger university population, potential faculty volunteers filled out an application form. The purpose of the form was threefold: 1) to control numbers of participants, (2) to 
ensure the greatest diversity among academic units, and, perhaps most importantly, (3) to ensure the greatest disparity between the two groups comprising each team.

As mentioned in Section 3.2, planning for the original studies was informed by the participatory design model, Cooperative Inquiry (CI) [12] which also involved intergenerational teams where the children team members were treated as complete equals with the adults. However, the CI model was predicated on the study of intergenerational teams that ran for long periods of time with the same members within a laboratory specially equipped for this purpose. Since the Bonded Design studies were to be conducted in an operational environment (a classroom over the lunch hour) the researchers had concerns regarding potential authority issues, specifically, how to maintain equality so that the students would feel comfortable; while still maintaining some control. To accomplish this, all team members called each other by their first names, and each group's expertise (the researchers in web portal design, the students in their unique worldviews and perspectives) respected.

In terms of the Faculty IT Liaison Program, while the university design teams were comprised of adults and there were therefore no authority concerns over age disparity, there were other power dynamics that needed to be considered, namely that IT professionals are considered support staff. At the outset of the project, it was not clear if or how this would make a difference to collaboration between these two very different groups within the design team sessions. Prior to the outset of the FITL the researchers held concerns such as; whether the faculty would "take charge" and condescend to the IT participants, would the two groups be able to share a common terminology when discussing technology, and would all participants feel comfortable and confident sharing their expertise? Fortunately, none of these concerns were realized.

\subsection{Design Sessions: Execution of Design Techniques}

As shown in Figure 1, in Bonded Design, the design techniques are executed in the following order: needs assessment, evaluation, discussion, brainstorming, prototyping and consensus building [5-7]. In the Faculty IT Liaison Program, however, because all team members had extensive experience using the technologies, many of these techniques were omitted, rearranged in order, and/or modified. This section will discuss indepth the developments of the Bonded Design methodology within the university with particular enhancements to the needs assessment, individual prototyping, individual brainstorming, and the consensus building techniques.

Needs Assessment. In the original studies, the Needs Assessment consisted of a short questionnaire that the young team members administered to their classmates during recess. Included as a design technique, it was mainly a team-building activity, although it did provide some insight into the students' design preferences for web portals. In the university, however, a survey sent out to all faculty members to identify and assess their technology needs and uses served as the needs assessment. Indeed, the results of this survey were the catalyst for the creation of the FITL Program, thus making the needs assessment a crucial part of the process instead of just an add-on activity. 
Individual Prototyping. Although not designated as a design technique in the intergenerational studies (it was included within the design technique of brainstorming) individual prototyping took place in the form of drawing one's own mental model of the ideal web portal. In the FITL Program, since technology evaluation and discussion were omitted for the reasons listed in the previous section, the sessions devoted to each technology started with this activity. As such, it was considered a separate design technique [26-27]. As might be expected, in the original studies the young students quite enjoyed the freedom of this activity, yet for some faculty members this task was not an enjoyable one. Unlike the children (and surprisingly, the IT staff participants who appeared happy to be able to think out of the box and dream), some faculty members were limited by their concerns that their ideas were not implementable, or that their drawing skills were poor.

Individual Brainstorming. In the intergenerational teams, this design technique consisted of drawing and presenting orally each team member's mental model of the ideal technology. The young students, although they enjoyed drawing very much, found brainstorming a more difficult exercise because they tended to interpret things at a very literal level $[5,6]$. Thus, features of each drawing were recorded and from these, the researchers developed a team prototype for the students to critique. In the FITL Program this technique was more complex. It started in the same way with individual oral presentations of each team member's drawing. It should be noted that often during these drawing presentations the level of enthusiasm of the discussions increased to the point where everyone was animatedly talking at once. This was likely stimulated by the fact that the researcher/facilitator, who is a terrible artist presented her drawing first. A further enhancement to the BD method for its use in the FITL Program was that each team member was asked to write down on sticky notes the three features (one per note) of their ideal system they felt were the most important. This differed from the intergenerational teams where the individual brainstorming phase ended with the presentations of drawings.

Consensus Building. In the intergenerational teams this technique consisted of discussing the low-tech prototype developed by the researchers. It was difficult for the students to reach consensus as they were loath to let go of their own ideas for the lowtech prototype however impractical or unpopular with the team as a whole they might have been. To achieve final consensus, the researchers had to include at least one feature of each child's drawing in the final design.

In the FITL Program, because of the sophisticated nature of the final deliverable recommendations for technology modifications - and the advanced educational levels of the FITL team members, consensus building was more complex. To begin, as a team, four to five categories relating to the workings of the technology (e.g., interface design, content organization) were identified. Each team member then categorized their ideas by affixing the sticky note under a category heading they believed to be the most appropriate. Consensus was achieved via team discussion where all of the ideas on the sticky notes were further fleshed out and depending on the team's decision, left alone, 
moved to another category, superseded by other similar ideas, or discarded. Consensus was fairly easily achieved, perhaps because many of the individual ideas were shared by other team members and because the deliverable, a list of recommendations and not one team design as in the intergenerational studies, allowed for expression of the majority of them.

Final Deliverable. As discussed earlier, the main purpose of the original studies was to establish whether participatory design methods could empower children and adults to work together in intergenerational teams to develop a low-tech prototype of a web portal for children. It was not important that the prototypes be useful, although they did inform the interface for a working web portal on Canadian History, History Trek. [21] Therefore, the results of the studies not only indicated that children and adults could effectively work together within a participatory design framework, but also that the process encouraged generation of creative and innovative ideas that each group would not have produced alone. These findings served as the catalyst for the creation of the Bonded Design methodology. In the university, however, the investigation concentrated on whether or not the Bonded Design methodology was an appropriate framework to enable efficient and effective development of an innovative, tangible deliverable that could be implemented.

\section{Bonded Design: The Evolution Realized}

Taking into consideration all of the issues raised in Section 3, a new model was developed to better reflect the Bonded Design methodology as realized in the Faculty IT Liaison Program. Figure 2 presents this new process flow where the needs assessment and the development of the final deliverable, rather than simply vehicles to encourage collaboration, comprise crucial elements of the methodology.

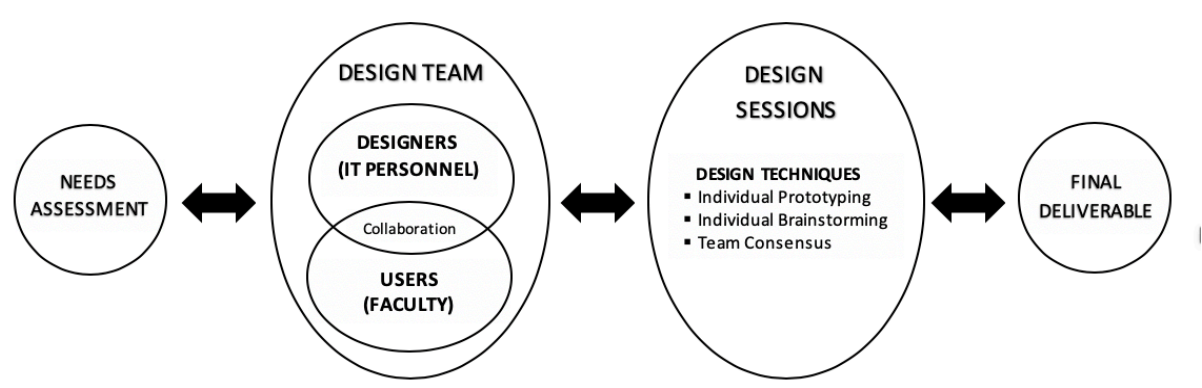

Fig. 2. Bonded Design Methodology - Faculty IT Liaison Program (C) 


\section{Conclusion}

The participatory design method, Bonded Design, developed from the findings of two studies of children and adults working together in intergenerational teams, was used as a framework for the Faculty IT Liaison Program, a university initiative. The FITL Program was established to encourage meaningful communication, interaction, and collaboration between faculty and IT professional staff. Unlike in the original studies [6-7], the participants in the FITL Program were all adults but from two very different groups, faculty and IT professional staff. The FITL Program was a demonstrated success as within the shared experience of the design team, these two disparate groups were able to come together to create recommendations for improving existing technologies that could not have been created alone or without the combination of teams with mixed areas of expertise. It has been reported by the University IT Department that many of these recommendations have been or will be incorporated into the technologies under consideration. Furthermore, the depth of collaboration enabled by the methods of Bonded Design was the catalyst in building upon the Bonded Design methodology to be used with disparate groups of adults. Indeed, future research funded by the US Institute of Museums and Library Services (IMLS) will investigate the efficacy of this new BD methodology in the public library context to enable librarians and older adults to work together to develop targeted and meaningful programming and services.

\section{References}

1. 2017 Faculty IT Survey, http://www.buffalo.edu/content/dam/www/ubit/docs/reports/2017FacultyITSurvey-Final.pdf, last accessed 2020/01/20.

2. Schuler, D., Namioka, A.: Participatory design: Principles and practices. L. Erlbaum Associates. Hillsdale, NJ (1993).

3. Carmel, E., Whitaker, R. D., George, J. F.: PD and joint application design: A transatlantic comparison. Communications of the ACM, 36(4), 40-48 (1993).

4. Muller, M., Kuhn, S.: PD. Communications of the ACM 36(6), 24-28 (1993).

5. Large, A., Nesset, V.: Bonded Design. In: Khosrow, M. (ed.) Encyclopedia of information science and technology, $2^{\text {nd }}$ edition. Information Science Reference, pp. 383-388. Hershey PA (2009).

6. Large, A., Nesset, V., Beheshti, J., Bowler, L.: "Bonded Design": A novel approach to intergenerational information technology design. Library and Information Science Research 28, 64-82 (2006).

7. Large, A., Nesset, V., Beheshti, J., Bowler, L. Bonded design: A methodology for designing with children. In: Zaphiris, P., Kurniawan, S. (eds.) Advances in universal web design and evaluation: research, trends and opportunities. pp. 73-96. Idea Group, Hershey PA (2007).

8. Torraco J.: Theory development research methods. In Swanson, R. A., Holden, E. F. (eds.) Research in Organizations: Foundations and Methods of Inquiry, pp. 351-374. Berrett Koehler Publishers, San Francisco, CA (2005).

9. Robertson T., Simonsen J.: Challenges and opportunities in contemporary participatory design. Design Issues 28(3), 3-9 (2012).

10. Marti P., Bannon L. J.: Exploring user-centered design in practice: Some caveats. Knowledge, Technology and Policy 22, 7-15 (2009). 
11. Bowler, L., Large, A. Design-based Research for LIS. Library and Information Science Research 30 39-46 (2009).

12. Druin, A.: Cooperative inquiry: Developing new technologies for children with children. In M. Williams, M. Altom (Chairpersons) Proceedings of the SIGCHI Conference on Human Factors in Computing Systems, pp. 592-599. ACM Press, New York, NY (1999).

13. Nesset, V., Large, A.: Children in the information technology design process: A review of theories and their applications. Library and Information Science Research 26(2), 140-161 (2004)

14. Yip, J. C., Clegg, T., Ahn, J., Uchidiuno, J. O., Bonsignore, E., Beck, A., Mills, K.: The Evolution of Engagements and Social Bonds During Child-Parent Co-design. In Proceedings of the 2016 CHI Conference on Human Factors in Computing Systems, pp. 3607-3619. ACM Press, New York, NY (2016).

15. McLaughlin, J. E.: Focus on user experience: Moving from a library-centric point of view. Internet Reference Services Quarterly 20(1/2), 33-60 (2015).

16. Nielsen Norman Group: How to collaborate with stakeholders in UX research. https://www.nngroup.com/articles/collaborating-stakeholders/, last accessed 01/20/2020

17. Bowler, L., Koshman, S., Oh, J. S., He, D., Callery, B. G., Bowker, G., Cox, R. J.: Issues in user-centered design in LIS. Library Trends 59(4), 721-752 (2011).

18. Atkins, L., Wallace, S.: Qualitative Research in Education. Sage Publications, London (2012).

19. Rapoport, R. N.: Three dilemmas in action research. Human Relations, 23, 499-514 (1970).

20. Wilson, V.: Research methods: Action research. Evidence Based Library and Information Practice, 8(4), 160-162 (2013).

21. Large, A., Beheshti, J., Nesset, V., Bowler, L.: Designing web portals in intergenerational teams: Two prototype portals for elementary school students. Journal of the American Society for Information Science and Technology 55(13), 1140-1154 (2004).

22. Soloway, E., Guzdial, M., Hay, K.: Learner-centered design: The challenge for HCI in the 21st century. Interactions 1(2), 36-48 (1994).

23. Guzdial M.: Learner-centered design of computing education: Research on computing for everyone. Morgan \& Claypool Publishers, San Rafael, CA (2016).

24. Scaife, M., Rogers, Y., Aldrich, F., Davies, M.: Designing for or designing with? Informant design for interactive learning environments. In Pemberton, S. (ed.), Proceedings of the SIGCHI Conference on Human Factors in Computing Systems, pp. 343-350. ACM Press, New York, NY (1997)

25. Beyer, H., Holtzblatt, K.: Contextual design. ACM Interactions 6, 32-42 (1999).

26. Nesset, V., Bible, J. B.: Building understanding between users and designers through participatory design: The Bonded Design approach. In: Chowdhury, G., McLeod, J., Gillet, V., Willett, P. (eds.) Transforming Digital Worlds. iCONFERENCE 2018, LNCS, vol 10766, pp. 515-520. Springer, Heidelberg (2018).

27. Nesset, V., Bible, J. B.: The Faculty IT Liaison Program: Using participatory design to build possibilities with technology. In Proceedings of ICKM '18: A Profession and Discipline of Action, University of North Texas, Denton, TX (2018). 